\title{
Genetic aspects of mammalian growth and survival in relation to body size
}

\author{
B Y ST C. S. TA YLOR \\ AFRC Institute of Animal Physiology \& Genetics Research, Edinburgh Research Station, Roslin, \\ Midlothian EH25 9PS
}

This presentation, summarized below, was based on a monograph published by the University of Queensland, with kind permission of Academic Press (Taylor \& Murray, 1987).

Mammalian traits of interest to ecologists and nutritionists, and of considerable relevance to animal production, are the amount of food ingested and metabolized; the growth of muscle, fat and bone; the yield of milk and wool; reproductive rate; survival rate; and whether the generation interval is short or long. All these traits are quantitative and most of them are related to body size (Taylor, 1965, 1968, 1980a, 1980b, 1980c, 1982, 1986). The relationships are surprisingly uniform over the whole mammalian range, so much so that they can largely be encapsulated in two formal genetic size-scaling rules. These can then be used to furnish a quantitative description of the growth of a typical mammal (Taylor, 1985). Genetic size-scaling is thus the body of theory that stems from the underlying physical, physiological and biochemical similarity of mammalian growth.

Genetic size-scaling depends on each genotype having its own genetic size factor, operating throughout growth from embryo to adult and expressing itself in many traits at every stage of growth. A convenient measure of this genetic size factor is a suitably standardized adult body-weight. Mammalian species differ in adult body-weight by a factor of about a million. Dog breeds differ by a factor of about 100 but, in most species, breeds show no more than a three-fold range in body-weight (of the same order of magnitude as the differences produced by nutrition). Genetic differences in traits such as food consumed and amount of lean meat produced during normal growth can be predicted from genetic differences in body size. The accuracy of many of these predictions is surprisingly high, yet the formulae are not widely used.

Genetic differences and similarities are discussed under nine headings: body size and biological time, the mean mammalian growth curve, body size and body composition in adult mammals, change in body composition during normal growth of a typical mammal, energy metabolism and body size, body size and food supply, reproduction abundance and survival, birth weight litter size and maternal performance, body size and lactation in a typical mammal.

\section{REFERENCES}

Taylor, St C. S. (1965). A relation between mature weight and time taken to mature in mammals. Animal Production 8, 203-220.

Taylor, St C. S. (1968). Time taken to mature in relation to mature weight for sexes, strains and species of domesticated mammals and birds. Animal Production 10, 157-169.

Taylor, St C. S. (1980a). Genetic size-scaling rules in animal growth. Animal Production 30, $161-165$.

Taylor, St C. S. (1980b). Genetically standardized growth equations. Animal Production 30, 167-175.

Taylor, St C. S. (1980c). Liveweight growth from embryo to adult in domestic mammals. Animal Production 31, 223-235. 
Taylor, St C. S. (1982). Theory of growth and food efficiency in relation to degree of maturity in body weight. In Proceedings of the 2nd World Congress on Genetics Applied to Livestock Production, pp. 218-230, October, 1982, Madrid.

Taylor, St C. S. (1985). The use of genetic size scaling in the evaluation of animal growth. Journal of Animal Science 61, Suppl. 2, 118-143.

Taylor, St C. S. (1986). Lifespan, metabolic age and genetics. In Proceedings XIII International Congress of Nutrition, pp. 683-685 [T. G. Taylor and N. K. Jenkins, editors]. London: John Libbey and Co.

Taylor, St C. S. \& Murray, J. I. (1987). A genetic review of mammalian food intake, growth, lactation, reproduction and survival in relation to body size. Butler Memorial Monograph. Brisbane. Australia: University of Queensland (with Academic Press). 